\title{
Long-term adverse effects on reproductive function in male rats exposed prenatally to the glucocorticoid betamethasone
}

\author{
Cibele dos S. Borges ${ }^{a, *}$, Ana Flávia M.G. Dias ${ }^{a}$, Patricia V. Silva ${ }^{a}$, Josiane Lima Rosa ${ }^{a}$, \\ Marina T. Guerra ${ }^{\mathrm{a}}$, Raquel F. Silva ${ }^{\mathrm{a}}$, Luiz Ricardo A. Kiguti ${ }^{\mathrm{b}}$, André S. Pupo ${ }^{\mathrm{b}}$, \\ Wilma De G. Kempinas ${ }^{a}$ \\ a Departments of Morphology, Institute of Biosciences of Botucatu, UNESP-Univ Estadual Paulista, Distrito de Rubião Junior s/n ${ }^{\circ}, 18618-689$ Botucatu, SP, \\ Brazil \\ ${ }^{\mathbf{b}}$ Departments of Pharmacology, Institute of Biosciences of Botucatu, UNESP-Univ Estadual Paulista, Distrito de Rubião Junior s/nº $18618-689$ Botucatu, SP, \\ Brazil
}

\section{A R T I C L E I N F O}

\section{Article history:}

Received 25 November 2015

Received in revised form 6 April 2016

Accepted 19 April 2016

Available online 27 April 2016

\section{Keywords:}

Betamethasone

Fetal programming

Sperm quality

Fertility

Sexual glands contractility

\begin{abstract}
A B S T R A C T
Betamethasone is the drug of choice for antenatal treatment, promoting fetal lung maturation, decreasing the incidence of respiratory distress syndrome and neonatal mortality. Previous studies reported that prenatal treatment with this drug reduced testosterone levels, sperm quality and fertility in adult rats. We aimed to further evaluate the reproductive consequences of prenatal betamethasone exposure in male rats. Pregnant Wistar rats ( $n=13$ /group) were separated into two groups: control (vehicle) and betamethasone- treated $(0.1 \mathrm{mg} / \mathrm{kg} \mathrm{IM})$ and rats were injected on gestational days 12,13 , 18 and 19. Body weight, sexual behavior, reproductive organ weights, serum hormone levels, accessory glands contractility, sperm parameters, and fertility after in utero artificial insemination were evaluated. Our results showed that prenatal betamethasone exposure provoked a significant reduction in body weight at PND 01 and, at adulthood, decrease in FSH levels, sperm motility and production. Furthermore, seminal vesicle weight was decreased while testicular and ventral prostate weights were increased. Serum LH levels and the percentage of abnormal sperm were significantly increased. Although sexual behavior was not altered, a significant reduction in fertility in the adult rats exposed prenatally to betamethasone was noted. We concluded that prenatal betamethasone exposure leads to long-term reproductive impairment in male rats. These results may have important implications for humans, considering the use of this glucocorticoid in pregnant women.
\end{abstract}

(C) 2016 Elsevier Ireland Ltd. All rights reserved.

\section{Introduction}

Fetal lung maturation is important before birth to avoid the respiratory distress syndrome, a serious complication of preterm birth and the primary cause of early neonatal death (Jobe and Soll, 2004; Roberts and Dalziel, 2007). The treatment used for women at risk of preterm birth to promote accelerating fetal lung maturation is denominated antenatal corticosteroid therapy, and the drug of choice is the glucocorticoid betamethasone (Drake et al., 2011).

Glucocorticoids play a key role in intrauterine programming, inducing permanent changes in physiological systems (Fowden and Forhead, 2004; Moisiadis and Matthews, 2014). (Fowden and Forhead, 2004; Moisiadis and Matthews, 2014). An important

\footnotetext{
* Corresponding author.

E-mail address: cibelesantosborges@gmail.com (C.d.S. Borges).
}

target of fetal programing is the reproductive system, once effects throughout the sexual development to adulthood can be observed.

The exposure to betamethasone in utero can promote changes in brain development (Yawno et al., 2014), renal function (Bi et al., 2014) and neuroendocrine alterations in different species (Matthews, 2000) as well as suppression of maternal and fetal adrenal (de Souza et al., 2001). Furthermore, the betamethasone was responsible for several alterations on male reproductive system, such as testis development in sheep (Pedrana et al., 2008; Pedrana et al., 2013) and sperm quality, fertility and testosterone levels when rats were exposed in utero at gestational days 12,13, 18 and 19 (Piffer et al., 2009a,b).

It is known that glucocorticoids, at high concentrations, can reduce fetal testosterone, which is fundamental for sexual differentiation (Corbier et al., 1992; Hardy et al., 2005; Page et al., 2001; Ward and Weisz, 1984). Thus, the present study 
investigated the long-term reproductive effects on male rats whose mothers were exposed to betamethasone during critical days of sexual development, with emphasis on sperm quality and fertility.

\section{Materials and methods}

\subsection{Animals}

Male (90 days old/300-350 g) and female (90 days old/225$230 \mathrm{~g}$ ) Wistar rats were obtained from the Multidisciplinary Center for Biological Investigation, State University of Campinas and maintained under controlled conditions $\left(25^{\circ} \mathrm{C}, 30 \%\right.$ air humidity, 12/12-h light/dark cycle) with food and water available ad libitum.

The experimental procedures used in this study were approved by the local Ethics Committee for the Use of Experimental Animals of the University of São Paulo State (protocol number 451-CEEA) in accordance with the Guide for the Care and Use of Laboratory Animals (National Institutes of Health). All surgical procedures were performed under ketamine-xylazine anesthesia and euthanasia performed by decapitation following $\mathrm{CO}_{2}$ asphyxiation.

\subsection{Experimental design}

Two nulliparous female rats were mated with one male, during the dark cycle of the photoperiod. The detection of sperm in the vaginal smear of rats in estrus was considered as gestational day 1 (GD1). Pregnant and lactating rats were maintained in individual cages.

Pregnant female rats were randomly allocated into two experimental groups: control (treated with saline - vehicle, $\mathrm{n}=11)$ and treated $(0.1 \mathrm{mg} / \mathrm{kg}$; Betamethasone 21-phosphate disodium - Sigma-Aldrich, St Louis, MO, diluted in vehicle, $\mathrm{n}=13$ ). This dose was selected based on the dose used in clinic for maternal treatment and modified to rodents (Piffer et al., 2009a,b). Rats received an intramuscular injection of vehicle or betamethasone on days 12,13, 18 and 19 of pregnancy. The injection protocol was based on the maternal corticosteroid therapy adapted by de Souza et al. (2001) which takes into account differences in the sexual differentiation in male fetuses (Pereira and Piffer, 2005; Pereira et al., 2003; Piffer et al., 2009a,b).

After birth, on post-natal day (PND) 1, the litters were cutoff for 8 animals per dam, 4 males and 4 females at random. Then, the male offspring was weighted. At PND 21, rats were housed in separate cages ( $n=4$ males per cage). For the experiments herein presented two male rats from each litter were used, divided into two studies.

\subsection{Study 1: sexual behavior, organ weights, hormones, sperm quality and fertility}

\subsubsection{Evaluation of male sexual behavior}

At PND 90, one male per litter was held placed in a cage alone for 5 min prior to the introduction of a sexually receptive female (70 days old). Paired animals were observed during the dark cycle of the photoperiod. Males that did not mount the female in the first 10 min were considered sexually inactive. Male sexual behavior was evaluated for $40 \mathrm{~min}$ and included the following parameters: latency to the first mount; latency to the first intromission; latency to the first ejaculation; number of intromissions until the first ejaculation; latency of the first post-ejaculatory intromission; number of post-ejaculatory intromissions; and total number of ejaculations.

\subsubsection{Organ weights}

Thirty days later, these same animals tested for sexual behavior were weighed and euthanized by $\mathrm{CO}_{2}$ asfixiation followed by decapitation. Then, blood was collected (9:00 and 11:30 AM) from the ruptured vessels and the right testis (intact and without the albuginea and fluid), epididymis, seminal vesicle (full and empty, without the coagulating gland), and ventral prostate were dissected out and weighed. The sexual glands were discarded. The parenchyma of right testis was obtained by cutting out the albuginea and removing the testicular fluid by centrifugation $\left(3000 \mathrm{rpm}\right.$ ) for $30 \mathrm{~min}$ at $4{ }^{\circ} \mathrm{C}$ and frozen at $-20^{\circ} \mathrm{C}$ for posterior sperm counts. The right epididymal cauda was used for sperm collection for intrauterine artificial insemination and the remainder tissue was frozen for sperm counts, as well as the epididymal caput/corpus. The left testis and epididymis were kept frozen for future studies.

\subsubsection{Fertility assessment}

Eight animals per group were used for fertility assessment using in utero artificial insemination (Kempinas et al., 1998a; Klinefelter et al., 1994). In brief, females in LHRH-induced proestrus were paired with sexually experienced vasectomized males for $1 \mathrm{~h}$. Receptive females were selected for the insemination procedure. Sperm were released from the right proximal epididymal cauda, first site where fertile sperm is encountered in the rat, by nicking the duct and collecting the sperm in 1-2 $\mathrm{ml}$ of modified human tubular fluid (HTF) medium (Irvine Scientific). After a 10fold dilution, sperm were counted and each uterine horn was injected with a volume containing $5 \times 10^{6}$ sperm. One female was inseminated per male and when insemination was completed, the abdominal musculature was sutured. All surgery was performed under ketamine-xylazine anesthesia, and all efforts were made to minimize suffering.

Twenty days later, the females were euthanized by decapitation to enable fertility evaluation. After collection of the uterus and ovaries the numbers of corpora lutea, implants and reabsorptions were recorded and the following endpoints determined: fertility potential (efficiency of implantation): implantation sites/corpora lutea $\times 100$; rate of pre-implantation loss: (number of corpora lutea - number of implantations/number of corpora lutea) $\times 100$; rate 4of post-implantation loss: (number of implantations - number of live fetuses)/number of implantations $\times 100$.

\subsubsection{Sperm motility}

Sperm motility was evaluated in the same sperm sample used for artificial insemination. For this, an aliquot of $10 \mu \mathrm{l}$ of sperm suspensions was immediately transferred to a Makler chamber maintained at $34^{\circ} \mathrm{C}$. Using a phase-contrast microscope ( $400 \times$ magnification), 100 sperm were counted and classified as Type $A$ (mobile with progressive movement) Type B (mobile without progressive movement) and Type C (immobile).

\subsubsection{Sperm morphology}

An aliquot of $100 \mu \mathrm{l}$ of the sperm suspension was added to $900 \mu \mathrm{l}$ of formol saline. To analyze sperm morphologically, smears were prepared on histological slides that were left to dry for $90 \mathrm{~min}$ and 200 spermatozoa per animal were analyzed in a phasecontrast microscope $(400 \times$ magnification). Morphological abnormalities were classified into two general categories: head morphology (without curvature, without characteristic curvature, pin head or isolated form, i.e., no tail attached) and tail morphology (broken or rolled into a spiral) (Filler, 1993). Sperm were also classified as to the presence or absence of the cytoplasmic droplet. 


\subsubsection{Serum hormonal levels}

Serum was obtained by centrifugation (2400 rpm) for $20 \mathrm{~min}$ at $4{ }^{\circ} \mathrm{C}$ and stored at $-20^{\circ} \mathrm{C}$. FSH and LH were assayed by doubleantibody method with specific kits provided by the National Hormone and Peptide Program (Harbor-University of California at Los Angeles). The primary antibody for FSH was anti-rat FSH-S11, and the reference was FSH-RP2. The antiserum for LH was anti-rat LH-S10 and the reference was RP3. The lower limit of detection for FSH and LH were 0.2 and $0.04 \mathrm{ng} / \mathrm{mL}$ and the intra-assay coefficients of variation were $3 \%$ and $3.4 \%$, respectively. Serum concentrations of testosterone were determined using specific kits provided by MP Biomedicals (Orangeburg, NY, USA). The lower limits of detection was $5 \mathrm{pg} / \mathrm{mL}$ and the intra-assay coefficient of variation was $4 \%$.

\subsubsection{Sperm counts, daily sperm production, and sperm transit time} through the epididymis

Homogenization-resistant testicular spermatids (stage 19 of spermiogenesis) were counted as described previously (Fernandez et al., 2008; Robb et al., 1978), with following adaptations: briefly, the testis, decapsulated and weighed soon after collection, was homogenized in $5 \mathrm{ml}$ of $\mathrm{NaCl} 0.9 \%$ containing Triton X 100 0.5\%, followed by sonication for $30 \mathrm{~s}$. After a 10 -fold dilution, one sample was transferred to Neubauer chambers (4 fields per animal), and mature spermatids were counted. To calculate the daily sperm production (DSP), the number of spermatids at stage 19 was divided by 6.1, which is the number of days of the seminiferous cycle during which these spermatids are present in the seminiferous epithelium. The caput/corpus and cauda epididymidis that were frozen as mentioned previously were cut into small fragments with scissors and homogenized, and sperm counted as described for the testis. The sperm reservoir in the cauda region was calculated by combining the number of cells in the sperm suspension and the sperm count in the homogenized tissue. The sperm transit time through the epididymis was determined by dividing the number of sperm in each portion by DSP.

\subsection{Study 2 - Pharmacological reactivity of isolated sexual glands}

Five rats per experimental group (one per litter) were weighed and euthanized at PND 90 by decapitation. A section of basal ventral prostate and a lobule of seminal vesicle were prepared for the in vitro tension recording as described below (Nojimoto et al., 2009). Tissues were mounted in $10 \mathrm{ml}$ organ baths in a modified Tyrode's solution at $30^{\circ} \mathrm{C}$ under $9.8 \mathrm{mN}$ resting tension and allowed a 30 min equilibration period. After the resting period, the tissues were repeatedly challenged with $80 \mathrm{mM} \mathrm{KCl}$ every $30 \mathrm{~min}$ until two reproducible contractions were obtained. After that, a cumulative concentration-response curve to norepinephrine (NE, $10^{-8} \mathrm{M}-10^{-4} \mathrm{M}$ ) and carbachol (CCh, $10^{-8} \mathrm{M}-3.10^{-4} \mathrm{M}$ ) were obtained at $30 \mathrm{~min}$ interval. The maximal tension developed (Emax, in milliNewtons, $\mathrm{mN}$ ) and the potency of NE and CCh in developing tension ( $\mathrm{pEC} 50$, the $-\log$ of agonist concentration inducing $50 \%$ of Emax) were evaluated.

\subsection{Statistical analysis}

Data are presented as mean \pm standard error of mean (SEM) or median and interquartile range. Student"s $t$-test was used for comparison of parametric variables. Nonparametric data were compared using Mann-Whitney test. Differences were considered significant when $\mathrm{p} \leq 0.05$. Statistical analyses were performed using the GraphPad InStat software (version 5).

\section{Results}

Prenatal betamethasone exposure provoked a significant reduction of male offspring weight at PND 1 (Fig. 1A) that did not persist at PND 120 (Fig. 1B).

Sexual behavior was not significantly altered by betamethasone treatment (Table 1). On the other hand, there was a significant reduction in the fertility potential as well as an increase in preimplantation loss after intrauterine insemination (Table 2).

The hormonal levels showed a significant increase in LH and a decrease in FSH levels in the betamethasone group (Fig. 2). Testicular and ventral prostate weights were significantly increased in the betamethasone group, while seminal vesicle weight was significantly decreased (Table 3 ). There was an increasing tendency, in the exposed group, in the difference between total testicular weight and testicular weight without the albuginea and fluid (control group: $0.47 \pm 0.04$; betamethasone group: $0.58 \pm 0.03 ; \mathrm{p}=0.07$ ).

In the bethametasone group there was a significant decrease in the percentage of progressive mobile sperm (Fig. 3A) and, consequently, an increase in percentage of mobile sperm without progressive trajectory in the betamethasone group (Fig. 3C). Furthermore, sperm with progressive motility and fertility potential were positively correlated (Fig. 3D). The percentages of morphologically abnormal sperm and sperm with cytoplasmic droplet increased (Table 4). The sperm transit time also increased in the betamethasone group (Table 5). On the other hand, daily sperm production and the number of sperm in the epididymal cauda were significantly decreased (Table 5).
A

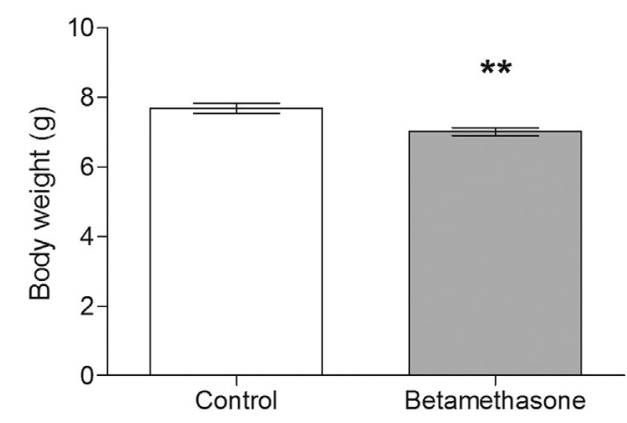

B

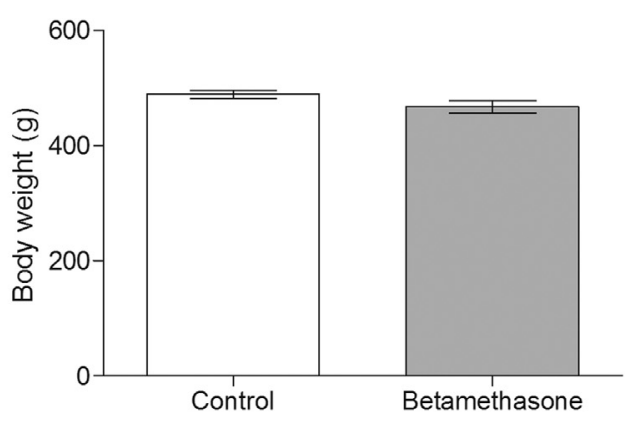

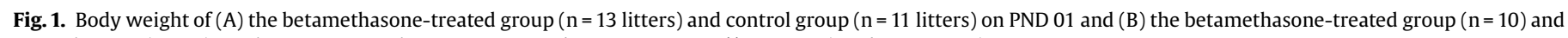
control group $(n=10)$ on the PND 120 . Values are expressed as mean \pm SEM. ${ }^{* *} \mathrm{p} \leq 0.01$ (Student"s $t$-test). 
Table 1

Male sexual behavior.

\begin{tabular}{|c|c|c|}
\hline Parameters & Control $(n=11)$ & Betamethasone $(n=13)$ \\
\hline Latency to the first mount (s) & $79.00(48.00-91.00)(n=11)$ & $69.00(46.00-105.00)(n=13)$ \\
\hline Number of mounts until the first ejaculation & $12.00(6.00-19.00)(n=11)$ & $13.00(9.50-18.00)(n=13)$ \\
\hline Latency to the first intromission (s) & $156.00(71.75-328.80)(n=10)$ & $152.50(81.00-244.80)(n=10)$ \\
\hline Number of intromissions until the first ejaculation & $46.00(27,25-66.75)(n=10)$ & $38.00(28.75-47.00)(n=10)$ \\
\hline Latency to the first ejaculation $(\mathrm{s})$ & $1581.00(1173.00-1794.00)(n=9)$ & $1124.00(761.00-1467.00)(n=9)$ \\
\hline Latency of the first post-ejaculatory mount (s) & $240.50(94.25-283.30)(n=8)$ & $252.50(198.00-290.30)(n=8)$ \\
\hline Number of post-ejaculatory mounts & $3.00(1.00-4.00)(n=8)$ & $3.00(1.25-9.00)(n=8)$ \\
\hline Latency of the first post-ejaculatory intromission (s) & $243.50(94.75-283.30)(\mathrm{n}=8)$ & $252.50(201.00-290.80)(n=8)$ \\
\hline Number of post-ejaculatory intromissions & $9.00(4.25-19.25)(n=8)$ & $11.50(8.50-13.75)(n=8)$ \\
\hline Total number of ejaculations & $1.00(1.00-2.50)(n=9)$ & $2.00(1.00-3.00)(n=9)$ \\
\hline Ejaculatory plugs (mg) & $63.70(56.05-86.50)(n=10)$ & $68.30(39.70-93.20)(n=11)$ \\
\hline
\end{tabular}

Values expressed as median and interquartile intervals (first to third). Mann-Whitney test.

Table 2

Fertility after artificial insemination.

\begin{tabular}{|c|c|c|}
\hline Parameters & Control $(n=07)$ & Betamethasone $(n=08)$ \\
\hline 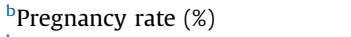 & 85.72 & 87.50 \\
\hline${ }^{\mathrm{b}}$ Fertility potential (\%) & 70.59 & $52.13^{*}$ \\
\hline${ }^{\mathrm{b}}$ Pre- implantation loss (\%) & 29.41 & $47.87^{*}$ \\
\hline${ }^{\mathrm{b}}$ Post- implantation loss (\%) & 29.69 & 16.67 \\
\hline${ }^{\mathrm{c} B o d y}$ weight of dams (g) & $304.30 \pm 3.09$ & $291.50 \pm 7.58$ \\
\hline${ }^{\mathrm{C}}$ Uterus weight with fetuses ( $\mathrm{g}$ ) & $8.25 \pm 0.79$ & $8.36 \pm 1.79$ \\
\hline${ }^{\mathrm{c}}$ Corpora lutea number & $11.33 \pm 0.84$ & $13.36 \pm 0.72$ \\
\hline${ }^{\mathrm{c}}$ Implantation number & $7.92 \pm 1.04$ & $6.93 \pm 1.44$ \\
\hline${ }^{\mathrm{c}}$ Reabsorption number & $2.42 \pm 0.95$ & $1.14 \pm 0.40$ \\
\hline${ }^{\mathrm{C}}$ Fetus weight (mg) & $315.70 \pm 7.43$ & $293.80 \pm 7.86^{\mathrm{a}}$ \\
\hline${ }^{\mathrm{c}}$ Placental weight (mg) & $258.20 \pm 7.71$ & $277.80 \pm 12.27$ \\
\hline
\end{tabular}

${ }^{*} \mathrm{p}<0.05$ (Chi-Square test)

a $\mathrm{p}=0.0712$.

b Values expressed as percentage.

c Values expressed as mean \pm SEM. (Student's t- test).

Fig. 4A shows that the potency of NE (adrenergic agonist) in inducing contractions in the isolated seminal vesicle was comparable between groups (control group: pEC50 $=5.431$ \pm 0.1618 ; betamethasone group: $\operatorname{pEC} 50=5.478 \pm 0.1235$ ). However, the maximal tension developed (Emax) for NE in the betamethasone group was increased compared to the control $(\mathrm{p}<0.05$, Fig. 4B). The same pattern was registered for CCh (Fig. 4C and D) a cholinergic agonist (control group: $\mathrm{pEC} 50=4.828$ \pm 0.1456 ; betamethasone group: $\mathrm{pEC} 50=4.790 \pm 0.1168$ ).

For ventral prostate (Fig. 5) the potency of NE (control group: pEC50 $=6.287 \pm 0.3704$; betamethasone group: pEC50 $=6.199$ $\pm 0.2846 ; \mathrm{p}>0.05$ ) and $\mathrm{CCh}$ (control group: $4.618 \pm 0.1251$; betamethasone group: $4.842 \pm 0.2281$; $p>0.05)$ were similar. In the same way, the Emax for NE and CCh were comparable between groups.

\section{Discussion}

In the past few years much has been discussed about the longterm effects caused by the intrauterine programming in physical and behavioral health of fetuses exposed to glucocorticoids, particularly betamethasone (Bi et al., 2014; Drake et al., 2011; Iqbal et al., 2012; Manojlovic'-Stojanoski et al., 2012; Pedrana et al., 2008, 2013; Piffer et al., 2009a,b; Yawno et al., 2014). In a previous work (Piffer et al., 2009a) we observed decrease in fertility after natural mating, lower sperm production, rate of normal morphology and motility, in adult rats whose mothers were exposed to betamethasone in critical periods of prenatal sexual differentiation. Considering the use of betamethasone as the drug of choice
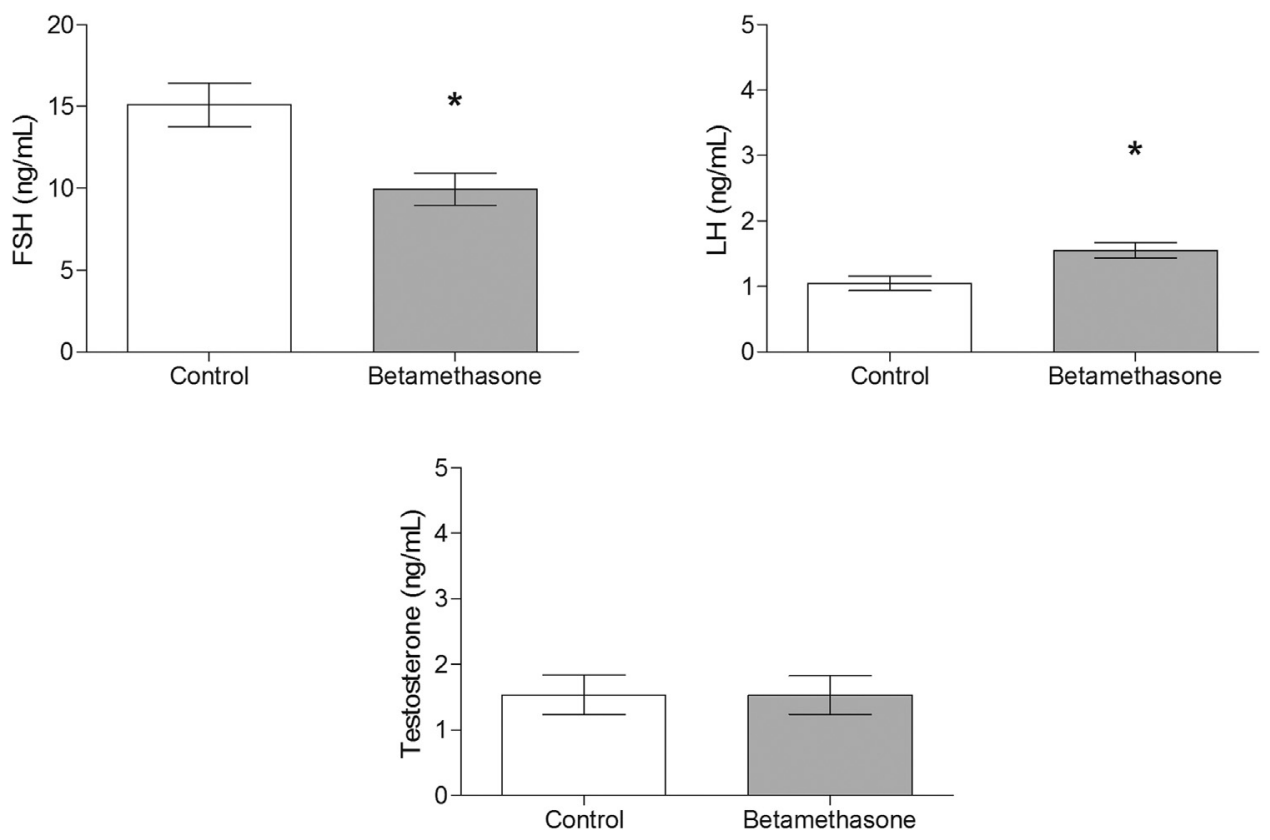

Fig. 2. Hormonal levels in the male offspring of treated and control groups on PND120. Values are expressed as mean \pm SEM. ${ }^{*} \mathrm{p} \leq 0.05$ (Student's $t$-test). 
Table 3

Body and organ weights.

\begin{tabular}{lll}
\hline Parameters & Control $(\mathrm{n}=11)$ & Betamethasone $(\mathrm{n}=13)$ \\
\hline Final body weight $(\mathrm{g})$ & $488.30 \pm 7.16$ & $467.10 \pm 10.60$ \\
Total testis (mg) & $1793.00 \pm 23.89$ & $1858.00 \pm 19.90^{*}$ \\
Parenchyma of testis (mg) & $1300.00 \pm 50.00$ & $1260.00 \pm 41.00$ \\
Testis (\%) & $0.37 \pm 0.01$ & $0.41 \pm 0.01^{* *}$ \\
Epididymis (mg) & $556.20 \pm 12.52$ & $556.90 \pm 11.12$ \\
Epididymis (\%) & $0.11 \pm 0.004$ & $0.12 \pm 0.003$ \\
Ventral prostate (mg) & $386.00 \pm 15.34$ & $457.40 \pm 21.67^{*}$ \\
Ventral prostate (\%) & $0.08 \pm 0.003$ & $0.10 \pm 0.004^{* *}$ \\
Seminal vesicle (mg) & $1266.00 \pm 48.69$ & $1163.00 \pm 49.43^{*}$ \\
Seminal vesicle (\%) & $0.26 \pm 0.011$ & $0.25 \pm 0.007$ \\
Seminal vesicle fluid (mg) & $923.10 \pm 44.86$ & $782.40 \pm 40.35^{*}$ \\
\hline
\end{tabular}

Values expressed as mean \pm SEM. Student"s $t$-test.

$\mathrm{p} \leq 0.05$.

$\mathrm{p} \leq 0.01$

for antenatal treatment for fetal lung maturation, in the present work we further investigated long-term effects of intrauterine betamethasone exposure on reproductive parameters of adult male rats.

Rodents produce an excess of qualitatively normal sperm (Amann, 1982). Intrauterine artificial insemination is a technique that increases the sensitivity of fertility tests and sperm quality evaluation (Amann 1986; Kempinas and Klinefelter, 2010), once this technique excludes the interference of factors such as altered sexual behavior pattern and reduction in ejaculated sperm number (Fernandez et al., 2008). In the present work the reduction in fertility potential and an increase of pre-implantation loss were observed in the group exposed to betamethasone. These results were probably due to the decrease in sperm motility and normal morphology, as shown by the positive correlation between these
Table 4

Sperm morphology.

\begin{tabular}{lll}
\hline Parameters & Control $(\mathrm{n}=10)$ & Betamethasone $(\mathrm{n}=10)$ \\
\hline $\begin{array}{l}\text { Normal sperm }(\%) \\
\text { Anormal sperm }(\%)\end{array}$ & $96.00(95.00-98.00)$ & $89.00(86.00-92.50)^{*}$ \\
$\quad$ Isolated head & $1.00(0.50-2.00)$ & $4.00(2.00-5.50)^{*}$ \\
$\quad$ Head without curvature & $2.00(0.00-3.50)$ & $5.00(1.00-8.00)$ \\
$\quad$ Broken tail & $0.50(0.00-1.00)$ & $1.50(0.00-3.25)$ \\
Cytoplasmic droplet (\%) & $25.00(17.50-26.00)$ & $31.00(28.50-36.50)^{*}$ \\
\hline
\end{tabular}

Values expressed as median and interquartile intervals (first to third).

" $\mathrm{p} \leq 0.05$ (Mann-Whitney test).

parameters, corroborating previously data on the betamethasone negative impact on sperm quality and fertility (Piffer et al., 2009a).

Betamethasone acts, directly, on genes and, indirectly, through changes in the bioavailability of several types of hormones. Since hormones regulate fetal growth and the development of individual fetal tissues, glucocorticoids have a central role in intrauterine programming (Moisiadis and Matthews, 2014), promoting changes that can be transient or persist into postnatal life (Manojlovic'Stojanoski et al., 2012; Matthews, 2000).

Glucocorticoids, when applied during gestation, affect gonadal function at multiple levels in hypothalamo-pituitary-gonadal axis. In the hypothalamus, decreasing the synthesis and release of GnRH. Inhibiting the synthesis and release of LH and FSH in the pituitary gland, and directly in the testis, modulating steroidogenesis and gametogenesis (Whirledge and Cidlowski, 2010). These same authors (Whirledge and Cidlowski, 2013) showed that glucocorticoids can inhibit directly testicular LH receptor numbers.

In the present work FSH was decreased and $\mathrm{LH}$ increased after prenatal betamethasone exposure, although testosterone, measured at adulthood, did not change, as well as the sexual
A

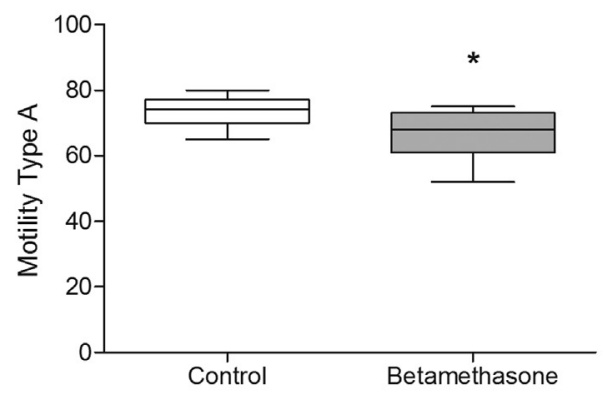

C



B



D

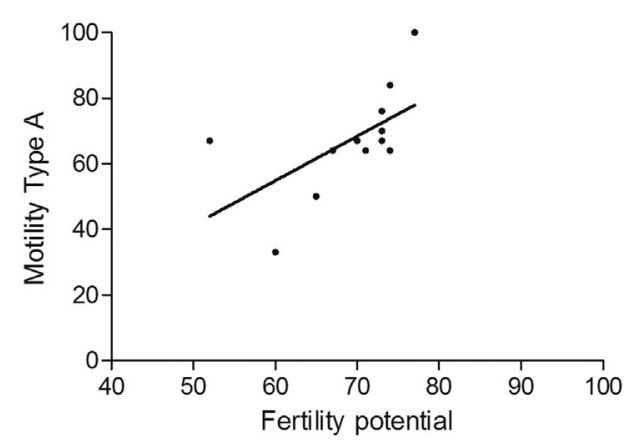

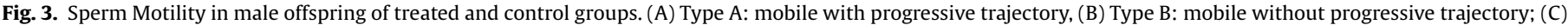

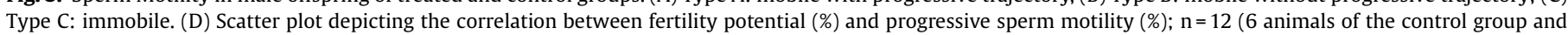
6 animals of the betamethasone-treated group). Values are expressed as median and interquartile intervals (first to third). ${ }^{*} \mathrm{p} \leq 0.05$, ${ }^{* *} \mathrm{p} \leq 0.01$ (Mann-Whitney test). 
Table 5

Sperm counts.

\begin{tabular}{|c|c|c|}
\hline Parameters & Control $(n=09)$ & Betamethasone $(n=10)$ \\
\hline \multicolumn{3}{|l|}{ Sperm count in the testis } \\
\hline Mature spermatids number (x106/testis) & $264.80 \pm 8.35$ & $197.30 \pm 23.11^{*}$ \\
\hline Relative spermatids number ( $\times 10^{6} / \mathrm{g} /$ testis $)$ & $203.70 \pm 5.36$ & $157.00 \pm 19.13^{*}$ \\
\hline Daily sperm production ( $\times 10^{6} /$ testis/day) & $43.35 \pm 1.35$ & $32.34 \pm 3.78^{*}$ \\
\hline Relative daily sperm production $\left(\times 10^{6} /\right.$ testis/g/day) & $33.39 \pm 0.87$ & $25.73 \pm 3.14^{*}$ \\
\hline \multicolumn{3}{|l|}{ Sperm count in the epididymis } \\
\hline Sperm number in caput/corpus ( $\times 10^{6} /$ organ $)$ & $95.09 \pm 8.14$ & $91.03 \pm 7.42$ \\
\hline Sperm number in cauda ( $\times 10^{6} /$ organ) & $234.60 \pm 11.28$ & $182.80 \pm 10.01^{*}$ \\
\hline Sperm transit time in caput/corpus (days) & $2.24 \pm 0.19$ & $3.57 \pm 0.77$ \\
\hline Sperm transit time in cauda (days) & $5.55 \pm 0.33$ & $7.71 \pm 1.30$ \\
\hline Total sperm transit time (days) & $7.78 \pm 0.46$ & $12.08 \pm 1.94^{*}$ \\
\hline
\end{tabular}

Values are expressed as mean \pm SEM.

$\mathrm{p}<0.05$ (Student's $t$-test).

behavior. Thus, it is possible that, throughout development, by a mechanism of adaptation, the pattern of synthesis of $\mathrm{LH}$ hormone changed, in order to guarantee normal testosterone levels in adulthood. On the other hand, the reduction in FSH levels can be correlated with the decrease in sperm production in the betamethasone group. It is known that this hormone is important for spermatogenesis and acts optimizing germ cell production (O'Shaughnessy, 2014).

The first change promoted by intrauterine betamethasone exposure is lowering birth weight (Braun et al., 2015; Fowden and Forhead, 2004). In the present work the decrease in body on PND 01 did not persist into adulthood, confirming data from the literature, in which fetuses with intrauterine growth restriction catchup development and accelerate weight gain during their postnatal development (Barker and Thornburg, 2013; Moisiadis and Matthews, 2014).

Alteration of the reproductive organ weights, an indicator of a toxic effect on reproduction (Clegg et al., 2001), can influence directly male sperm quality and fertility.

Sperm motility and fertility capacity are acquired during epididymal transit, under the control of androgens and sympathetic innervations (Kempinas et al., 1998a,b; Robaire et al., 2006). It is known that acceleration of epididymal sperm transit time can lead to lower sperm quality (Fernandez et al., 2008; Klinefelter and Suarez, 1997). Thus, the reduction of sperm quality observed in the intrauterine betamethasone exposed group might be due to an alteration on luminal epididymal microenvironment (for review, see De Grava Kempinas and Klinefelter, 2014).
A

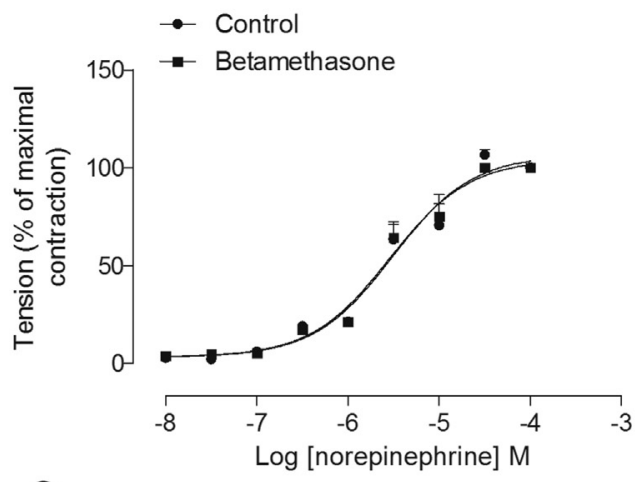

C

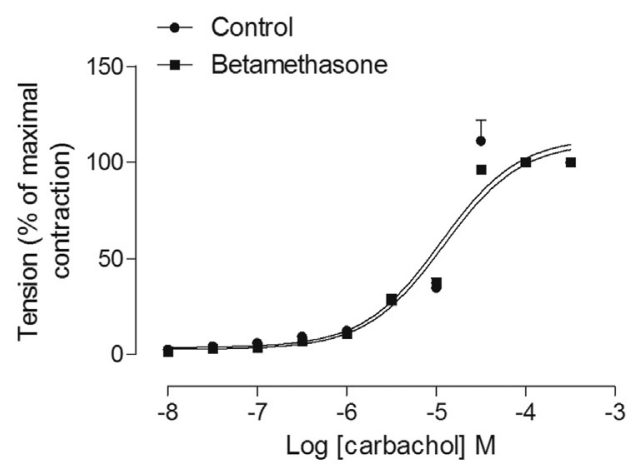

B

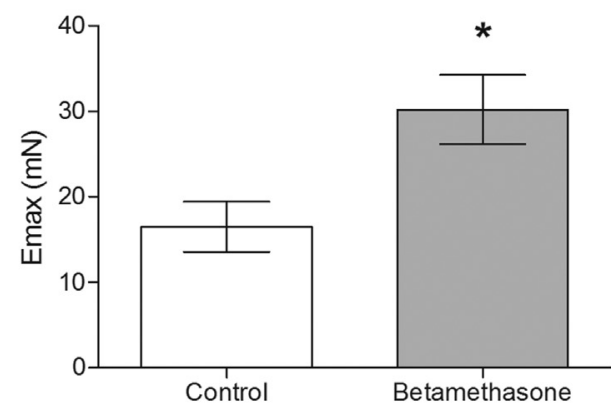

D

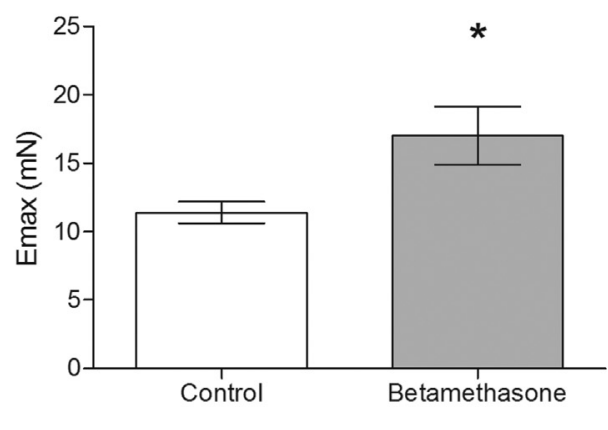



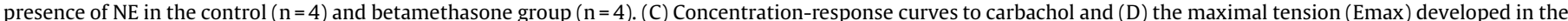

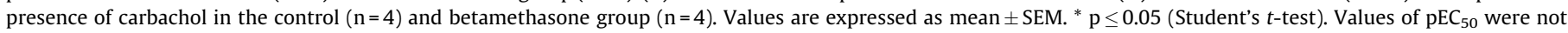
different between NE curves (ANOVA, followed by Dunnett). 
A

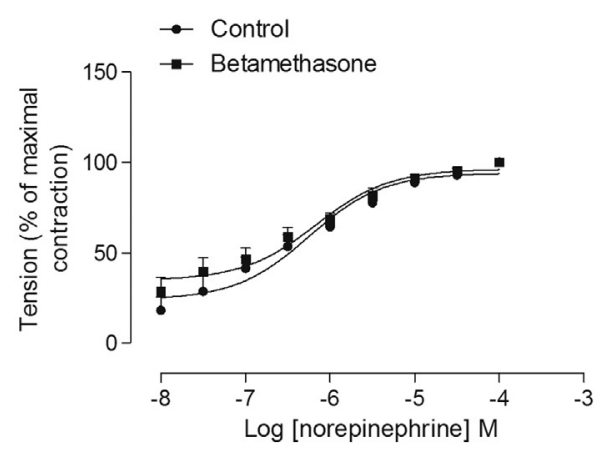

C

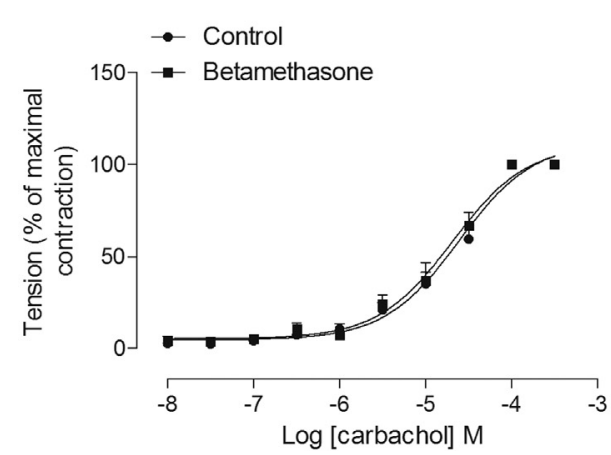

B
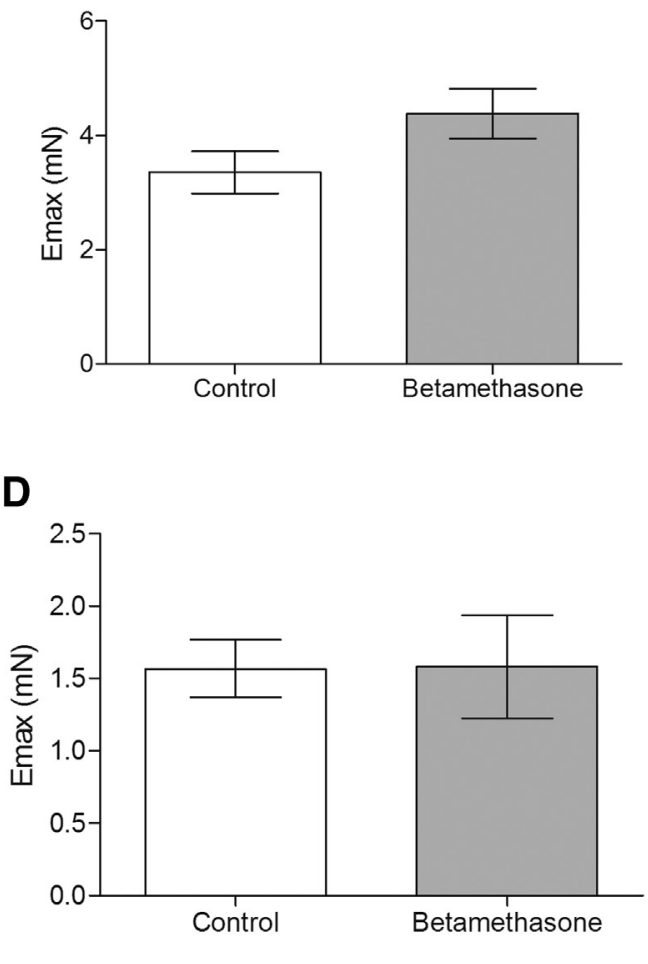

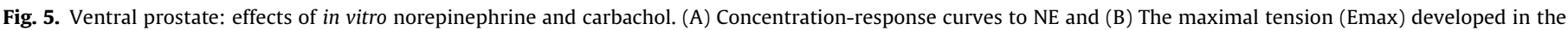

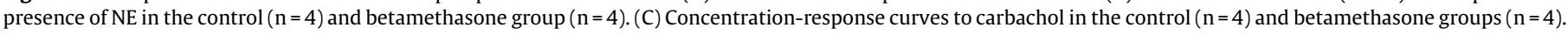
Values are expressed as mean \pm SEM. ${ }^{*} \mathrm{p} \leq 0.05$ (Student's $t$-test). Values of $\mathrm{pEC}_{50}$ were not different between NE curves (ANOVA, followed by Dunnett).

In this study, prenatal betamethasone treatment was associated with reduced seminal vesicle fluid with no alteration in the seminal vesicle parenchyma. During the emission phase of ejaculation, the seminal fluids produced by the seminal vesicles and prostate are deposited into the urethra by rhythmic contractions of smooth muscle induced by sympathetic and parasympathetic nervous system (Giuliano and Clement, 2005). These contractions are induced by activation of $\alpha_{1}$-adrenoceptors and muscarinic acetylcholine receptors by released norepinephrine and acetylcholine, respectively (Fedan et al., 1977; Pennefather et al., 2000). Thus, the seminal vesicles from betamethasone-treated rats presented increased contraction to $\alpha_{1}$-adrenoceptor and muscarinic acetylcholine receptor activation suggesting the decreased fluid amount remaining in the seminal vesicles could be a result, at least in part, of increased output during the ejaculation.

Interestingly, these effects of prenatal betamethasone on genital smooth muscle contractility seems to be organ-specific, since the prostate contraction to $\alpha_{1}$-adrenoceptor and muscarinic acetylcholine receptor activation were not changed. The increase of ventral prostate weight observed in this current work could be correlated to the higher LH levels, once this hormone acts on glandular epithelium increasing fluid production and/or promotes prostate hypertrophy (Ponglowhapan et al., 2012; Reiter et al., 1999).

Glucocorticoids have been shown to program testicular function permanently (Pedrana et al., 2008, 2013). In the current work, testicular weight was significantly increased in the betamethasone group. Taken into consideration that in these same animals there was a decrease in sperm production, it is possible this effect results from fluid accumulation, once we noted a difference between the total testicular weight and testicular parenchyma, but this hypothesis needs to be further investigated.

In conclusion, prenatal betamethasone exposure leads to longterm reproductive impairment in male rats. These results may be probably due to intrauterine programming and have important implications for humans, considering the use glucocorticoids in pregnant women.

\section{Acknowledgments}

We are grateful by the financial support by FAPESP - The State of São Paulo Research Foundation [Grant numbers 2012/25350-1 and 2013/26557-1] and CNPq - National Council for Scientific and Technological Development [Grant number 308842/2013-8].

Furthermore, we wish to acknowledge to Dr. Janete AnselmoFranci and to Dr. Ruither de Oliveira Gomes Carolino of the Department of Morphology, Stomatology and Physiology, Dental School of Ribeirão Preto, University of São Paulo - USP, for the collaboration with the hormonal assays and to José Eduardo Bozano, assisting academic support, of the Department of Morphology, Institute of Biosciences of Botucatu, UNESP, for the collaboration and assistance throughout the study.

\section{References}

Amann, R.P., 1982. Use of animal models for detecting specific alterations in reproduction. Fundam. Appl. Toxicol. 2, 13-26.

Amann, R.P., 1986. Detection of alterations in testicular and epididymal function in laboratory animals. Environ. Health Perspect. 70, 149-158.

Barker, D.J., Thornburg, K.L., 2013. Placental programming of chronic diseases, cancer and lifespan: a review. Placenta 34, 841-845.

Bi, J., Contag, S.A., Chen, K., Su, Y., Figueroa, J.P., Chappell, M.C., Rose, J.C., 2014. Sexspecific effect of antenatal betamethasone exposure on renal oxidative stress 
induced by angiotensins in adult sheep. Am. J. Physiol. Ren. Physiol. 307, F1013F1022.

Braun, T., Sloboda, D.M., Tutschek, B., Harder, T., Challis, J.R., Dudenhausen, J.W., Plagemann, A., Henrich, W., 2015. Fetal and neonatal outcomes after term and preterm delivery following betamethasone administration. Int. J. Gynaecol. Obstet. 130, 64-69.

Clegg, E.D., Perreault, D., Klinefelter, G.R., 2001. Assessment of male reproductive toxicity. In: Hayes, A.W. (Ed.), Principles and Methods of Toxicology, pp. 12631300.

Corbier, P., Edwards, D.A., Roffi, J., 1992. The neonatal testosterone surge: a comparative study. Arch. Int. Physiol. Biochim. Biophys. 100,127-131.

De Grava Kempinas, W., Klinefelter, G.R., 2014. Interpreting histopathology in the epididymis. Spermatogenesis 4, e979114.

de Souza, E., Kobayashi, S., de Jesus Simões, M., Camano, L., Kulay Júnior, L., 2001. Aõúo da Betametasona em Ratas Prenhes: Impacto sobre os Nçveis de Corticosterona e Glãndulas Adrenais Maternas e Fetais. Revista Brasileira de Ginecologia e Obstetrçcia 23, 667-673.

Drake, A.J., Liu, L., Kerrigan, D., Meehan, R.R., Seckl, J.R., 2011. Multigenerational programming in the glucocorticoid programmed rat is associated with generation-specific and parent of origin effects. Epigenetics 6, 1334-1343.

Fedan, J.S., Besse, J.C., Carpenter, F.G., Teague, R.S., 1977. Motor innervation of the smooth muscle of the rat seminal vesicle. J. Pharmacol. Exp. Ther. 201, 285-297.

Fernandez, C.D., Porto, E.M., Arena, A.C., Kempinas Wde, G., 2008. Effects of altered epididymal sperm transit time on sperm quality. Int. J. Androl. 31, 427-437.

Filler, R., 1993. Methods for evaluation of rats epididymal sperm morphology. In: Chapin, J.H.H.R.E. (Ed.), Male Reproductive Toxicology. Academic Press, California, pp. 334-343.

Fowden, A.L., Forhead, A.J., 2004. Endocrine mechanisms of intrauterine programming. Reproduction $127,515-526$.

Giuliano, F., Clement, P., 2005. Physiology of ejaculation: emphasis on serotonergic control. Eur. Urol. 48, 408-417.

Hardy, M.P., Gao, H.B., Dong, Q., Ge, R., Wang, Q., Chai, W.R., Feng. X., Sottas, C., 2005. Stress hormone and male reproductive function. Cell Tissue Res. 322, 147-153.

Iqbal, M., Moisiadis, V.G., Kostaki, A., Matthews, S.G., 2012. Transgenerational effects of prenatal synthetic glucocorticoids on hypothalamic-pituitary-adrenal function. Endocrinology 153, 3295-3307.

Jobe, A.H., Soll, R.F., 2004. Choice and dose of corticosteroid for antenatal treatments. Am. J. Obstet. Gynecol. 190, 878-881.

Kempinas, W.D.G., Klinefelter, G.R., 2010. The epididymis as a target for toxicants. Compr. Toxicol. 149-166.

Kempinas, W.D., Suarez, J.D., Roberts, N.L., Strader, L., Ferrell, J., Goldman, J.M., Klinefelter, G.R., 1998a. Rat epididymal sperm quantity, quality, and transit time after guanethidine-induced sympathectomy. Biol. Reprod. 59, 890-896.

Kempinas, W.D., Suarez, J.D., Roberts, N.L., Strader, L.F., Ferrell, J., Goldman, J.M., Narotsky, M.G., Perreault, S.D., Evenson, D.P., Ricker, D.D., Klinefelter, G.R., 1998b. Fertility of rat epididymal sperm after chemically and surgically induced sympathectomy. Biol. Reprod. 59, 897-904.

Klinefelter, G.R., Suarez, J.D., 1997. Toxicant-induced acceleration of epididymal sperm transit: androgen-dependent proteins may be involved. Reprod. Toxicol. 11, 511-519.

Klinefelter, G.R., Laskey, J.W., Perreault, S.D., Ferrell, J., Jeffay, S., Suarez, J., Roberts, N., 1994. The ethane dimethanesulfonate-induced decrease in the fertilizing ability of cauda epididymal sperm is independent of the testis. J. Androl. 15, 318-327.

Manojlovic'-Stojanoski, M., Nestorovic', N., Miloševic, V., 2012. Prenatal glucocorticoids: short-term benefits and long-term risks. In: Qian, X. (Ed.), Glucocorticoids-New Recognition of Our Familiar Friend.

Matthews, S.G., 2000. Antenatal glucocorticoids and programming of the developing CNS. Pediatr. Res. 47, 291-300.
Moisiadis, V.G., Matthews, S.G., 2014. Glucocorticoids and fetal programming part 1: outcomes. Nat. Rev. Endocrinol. 10, 391-402.

Nojimoto, F.D., Piffer, R.C., Kiguti, L.R., Lameu, C., de Camargo, A.C., Pereira, O.C., Pupo, A.S., 2009. Multiple effects of sibutramine on ejaculation and on vas deferens and seminal vesicle contractility. Toxicol. Appl. Pharmacol. 239, 233240.

O'Shaughnessy, P.J., 2014. Hormonal control of germ cell development and spermatogenesis. Semin. Cell Dev. Biol. 29, 55-65.

Page, K.C., Sottas, C.M., Hardy, M.P., 2001. Prenatal exposure to dexamethasone alters Leydig cell steroidogenic capacity in immature and adult rats. J. Androl. 22, 973-980.

Pedrana, G., Sloboda, D.M., Perez, W., Newnham, J.P., Bielli, A., Martin, G.B., 2008. Effects of pre-natal glucocorticoids on testicular development in sheep. Anat. Histol. Embryol. 37, 352-358.

Pedrana, G., Viotti, M.H., Souza, E., Sloboda, D., Martin, G.B., Cavestany, D., Ortega, H. H., 2013. Apoptosis-Related protein expression during pre- and post-Natal testicular development after administration of glucocorticoid in utero in the sheep. Reprod. Domest. Anim. 48, 795-802.

Pennefather, J.N., Lau, W.A., Mitchelson, F., Ventura, S., 2000. The autonomic and sensory innervation of the smooth muscle of the prostate gland: a review of pharmacological and histological studies. J. Auton. Pharmacol. 20, 193-206.

Pereira, O.C., Piffer, R.C., 2005. Puberty installation and adrenergic response of seminal vesicle from rats exposed prenatally to hydrocortisone. Life Sci. 77, $1381-1390$.

Pereira, O.C.M., Arena, A.C., Yasuhara, F., Kempinas, W.G., 2003. Effects of prenatal hydrocortisone acetate exposure on fertility and sexual behavior in male rats. Regul. Toxicol. Pharm. 38, 36-42.

Piffer, R.C., Garcia, P.C., Gerardin, D.C., Kempinas, W.G., Pereira, O.C., 2009a. Semen parameters, fertility and testosterone levels in male rats exposed prenatally to betamethasone. Reprod. Fertil. Dev. 21, 634-639.

Piffer, R.C., Garcia, P.C., Pereira, O.C., 2009b. Adult partner preference and sexual behavior of male rats exposed prenatally to betamethasone. Physiol. Behav. 98, $163-167$.

Ponglowhapan, S., Church, D.B., Khalid, M., 2012. Expression of luteinizing hormone and follicle-stimulating hormone receptor in the dog prostate. Theriogenology 78, 777-783.

Reiter, E., Hennuy, B., Bruyninx, M., Cornet, A., Klug, M., McNamara, M., Closset, J. Hennen, G., 1999. Effects of pituitary hormones on the prostate. Prostate 38, 159-165.

Robaire, B., Hinton, B.T., Orgebin-Crist, M.C., 2006. The epididymis. In: Neill, J.D. (Ed.), Knobil and Neill's Physiology of Reproduction. Elsevier, pp. 1071-1148.

Robb, G.W., Amann, R.P., Killian, G.J., 1978. Daily sperm production and epididymal sperm reserves of pubertal and adult rats. J. Reprod. Fertil. 54, 103-107.

Roberts, D., Dalziel, S., 2007. Antenatal corticosteroids for accelerating fetal lung maturation for women at risk of preterm birth. Obstet. Gynecol. 109, 189-190

Ward, I.L. Weisz.J., 1984. Differential-effects of maternal stress on circulating levels of corticosterone, progesterone, and testosterone in male and female rat fetuses and their mothers. Endocrinology 114, 1635-1644.

Whirledge, S., Cidlowski, J.A., 2010. Glucocorticoids, stress, and fertility. Minerva Endocrinol. 35, 109-125.

Whirledge, S., Cidlowski, J.A., 2013. A role for glucocorticoids in stress-impaired reproduction: beyond the hypothalamus and pituitary. Endocrinology 154, $4450-4468$.

Yawno, T., Mortale, M., Sutherland, A.E., Jenkin, G., Wallace, E.M., Walker, D.W., Miller, S.L., 2014. The effects of betamethasone on allopregnanolone concentrations and brain development in preterm fetal sheep. Neuropharmacology 85, 342-348. 